\title{
Uma Experiência Pioneira em Ensino de Ciências da Saúde via Internet na Marinha do Brasil
}

\section{A Pioneering experience in Health Sciences teaching using the internet in the Navy of Brazil}

\author{
${ }^{1}$ Raul Luiz de Souza Cavalcanti prof.raul.cavalcanti@gmail.com \\ ${ }^{1}$ Renato Matos Lopes \\ ${ }^{1}$ Thaís Faggioni \\ ${ }^{1}$ Luiz Anastácio Alves \\ ${ }^{2}$ Luiza Rodrigues de Oliveira
}

\section{RESUMO}

O presente artigo apresenta a estrutura e avalia um curso de Suporte Básico de Vida de ensino a distância, desenvolvido pela Escola de Saúde do Hospital Naval Marcílio Dias da Marinha do Brasil. Através da técnica da análise do discurso, cinco Sargentos Enfermeiros, profissionais de enfermagem de nível médio, que participaram do curso foram escolhidos aleatoriamente para responder entrevistas semiestruturadas para obter informações acerca da percepção deles sobre o curso, assim como o mesmo influenciou a prática desses profissionais de Saúde. Nesta etapa, foram utilizados a análise de discurso para interpretação de dados, onde verificou-se que a utilização de recursos tecnológicos por meio da rede mundial de computadores, veio facilitar o acesso ao conhecimento desses militares, principalmente, dos que se encontram distantes de pólos educacionais presenciais. O Curso “Suporte Básico de Vida à Distância”, via web, é pioneiro nas Forças Armadas nesta modalidade, atendendo não só aos militares locais, como também àqueles lotados em unidades de outros estados. A importância desse curso se deve por ser utilizado até os dias atuais, com a intenção em manter profissionais militares preparados para atuação em situações que exijam conhecimento sobre o atendimento às vítimas com risco de vida, operando em missões que envolvam situações de emergência e exijam padrões internacionais de atendimento a essas vítimas.

Palavras-chave: Ensino à Distância. Internet na Educação. Educação.

\section{ABSTRACT}

This paper presents the structure and evaluates a Distance Learning course of Basic Life Support, developed by the Health School of Marcilio Dias Hospital from Brazilian Navy. Through the technique of discourse analysis, five Sergeants Nurses, nurse practitioners middle level, who attended the course, were randomly chosen to answer structured interviews to obtain information on their perception of the course, as it hasinfluenced their practice.In this step, we used discourse analysis to interpret the data, thus, we found that the use of technology resources, through the World Wide Web, has facilitated access to knowledge of these soldiers, especially those who are far from educational classroom. Distance Learning course of Basic Life Support ", via web, is a pioneer in the Armed Forces in this mode, serving not only the local military, as well as those units stationed in other states. The importance of this course is due to be used until the present day, with the intent on keeping military professionals prepared to work in situations that require knowledge about caring for victims with life-threatening missions involving operating in emergency situations and require international standards to assistance to these victims.

Keywords: Distance Learning, Internet in Education, Education.

1 Laboratório de Comunicação Celular, Instituto Oswaldo Cruz - FIOCRUZ.

2 Instituto Superior de Educação do Rio de Janeiro - ISERJ 


\section{INTRODUÇÃO}

Modificações significativas na sociedade foram observadas a partir do momento em que os computadores se tornaram disponíveis nos anos de 1950. A forma como a economia passou a ser movimentada, assim como o desenvolvimento das ciências, foram profundamente modificados com o uso dos computadores (Flyn, 2002). Nesse contexto, apresenta-se a Internet que, ao final de 2011, possuía mais de 2 bilhões de usuários em todo o Mundo (Stats, 2012). A Internet alavanca a economia e a informação online é cada vez mais produzida e compartilhada (Silva, 2006). Através da Internet, Educação à Distância ou Ensino à Distância (Belloni, 2009) ganhou grande importância.O Decreto 5.622, que regulamenta o Artigo 80 da Lei no 9.394, de 20 de dezembro de 1996, estabelece Educação à Distância (EaD) como uma "modalidade educacional na qual a mediação didático-pedagógica nos processos de ensino e aprendizagem ocorre com a utilização de meios e tecnologias de informação e comunicação, com estudantes e professores desenvolvendo atividades educativas em lugares ou tempos diversos". Entretanto, é importante ressaltar que o EaD pode ocorrer de diversas formas: por correspondência, via correio ou fax, pelas transmissões por TV ou rádio, por vídeo conferência, com a utilização de vídeo cassetes, CD e DVD.

Nunes (2009) ressalta que um curso a distância não é mais um curso por correspondência unidirecional, em que se enviam livros e textos pelo correio e se espera que o aluno já saiba estudar e aprender. O autor esclarece que o ensino à distância é voltado especialmente (mas não exclusivamente) para adultos que, em geral, já estão no mundo corporativo e necessitam estudar a fim de completar sua formação inicial ou continuada. Portanto, a partir das ferramentas disponibilizadas em uma Plataforma de Ambiente Virtual de Aprendizagem (AVA), tais como as plataformas Moodle ou TelEduc, o aluno poderá interagir em tempo real com outros alunos e professores no processo de construção do conhecimento. Importante ressaltar que o EaD é um processo fundamental na atualização e aprimoramento dos profissionais do campo da Saúde das diversas Organizações Militares (OM) da Marinha do Brasil, em especial daquelas que se encontram em constante embarque marítimo resultante de exercícios e missões militares.

Neste trabalho apresentamos a construção, análise e reformulação de um curso de EaD para profissionais de Enfermagem de nível médio, Militares que atuam na Marinha do Brasil.

\section{O CONTEXTO: O EAD NA MARINHA E A ESCOLA DE SAÚDE DO HOSPITAL NAVAL MARCÍLIO DIAS}

A Marinha do Brasil tem uma tradição na história da Educação à Distância. A Escola de Guerra Naval (EGN) criou um curso por correspondência em 22/11/1939 com o objetivo de preparar Oficiais para a matrícula no "Curso de Comando". Em 1940, o curso por correspondência passou à categoria de "Curso Preliminar", sendo criado o "Curso de Alto Comando" que abordava os mais elevados assuntos militares. A partir de 1947 foram realizadas modificações na estrutura de ensino da EGN, sendo criado o "Curso Superior por Correspondência". Em 1971 foi criado o Curso Básico, atual Curso de Estado-Maior para Oficiais Intermediários (C-EMOI) que, na sua estrutura atual, compõe-se pelas fases por correspondência e presencial. Em 2003, a EGN iniciou a sua primeira experiência de curso via Intranet, com o oferecimento de uma disciplina do Curso Superior (C-SUP). Em 2005, todas as disciplinas do C-SUP passaram a ser oferecidas via Internet. No âmbito da formação das Praças, em 1978 foi criado o Curso Especial de Habilitação a Suboficial, por correspondência, no Centro de Instrução Almirante Wandenkolk (CIAW), atualmente realizado no Centro de Instrução Almirante Alexandrino (CIAA) (DEnsM-5001, 2005).

Em 2001, a Diretoria de Ensino da Marinha (DEnsM) iniciou estudos para a implementação do EaD via web, criando o Núcleo de Ensino à Distância (NEAD), atualmente Departamento de Ensino à Distância (DEAD), responsável pelo planejamento, coordenação e controle das atividades de EaD nas OM do Sistema de Ensino Naval (SEN). Em 2003, a DEnsM criou o curso Expedito de Capacitação de Autores e Tutores de EaD 
(C-EXP-CATEAD) com o objetivo de orientar Oficiais, Praças e Civis assemelhados, que atuarão no EaD para o exercício de autoria e tutoria de EaD, bem como no desenvolvimento de material didático a ser utilizado em cursos à distância via web.

Importante ressaltar que a área de saúde militar, que inclui a Enfermagem Militar, difere do meio civil por tratar de problemas associados às atividades de combate e aquelas voltadas para o estudo das operações prolongadas em meio marítimo e aéreo, bem como em regiões de climas adversos (Antártica e Amazônia), além das resultantes do uso de armas nucleares táticas e operações conjuntas com outras Forças ou Nações, tanto em treinamento quanto em situações reais. Além dos hospitais, ambulatório e centros odontológicos, o Corpo de Saúde da Marinha está presente em Navios de Assistência Hospitalar, quartéis e estabelecimentos de ensino.

A Escola de Saúde do Hospital Naval Marcílio Dias (HNMD), localizada no Rio de Janeiro, foi criada em 1979 através do Decreto nº 8.316, de 12/02/1979, e integrada ao Sistema de Ensino Naval (SEN) pela Lei $\mathrm{n}^{0}$ 5450/79. Possui, atualmente, um corpo discente de aproximadamente 400 alunos, distribuídos nos seguintes cursos e estágios: Aperfeiçoamento para Oficiais Médicos, Dentistas, Farmacêuticos e Enfermeiros, Residência Médica e em Enfermagem, Pós-Graduação strictu e lato sensu no país e no exterior, Medicina de Aviação, Medicina de Mergulho, Aperfeiçoamento e Especialização para Praças nas áreas de Enfermagem, Patologia Clínica, Banco de Sangue, Gasoterapia, Radiodiagnóstico, Medicina Nuclear, Medicina Hiperbárica, Prótese Odontológica, Radioterapia, entre outras (Marinha do Brasil, 2004, p.10)

Embora vinculada ao SEN, a Escola de Saúde busca equiparar sua formação à legislação educacional civil, uma vez que foi por intermédio do Parecer n 290/85, da Secretaria Estadual de Educação do Rio de Janeiro, que recebeu seu credenciamento, bem como a autorização de funcionamento. Em 2004, seus cursos de Enfermagem foram cadastrados junto ao Ministério da Educação através do Cadastro Nacional de Cursos Técnicos (CNCT).

\section{O CURSO DE SUPORTE BÁSICO DE VIDA (SBV)}

A criação, na Escola de Saúde do HNMD, de cursos à distância para Praças, surge da necessidade de mantê-los atualizados, já que atuam nas diversas Unidades de Assistência Médico-Hospitalar da Marinha do Brasil. Tem como objetivo suplementar a qualidade técnico-profissional desses militares, habilitando-os para o exercício das funções que exijam conhecimentos em Suporte Básico de Vida (ou Basic Trauma Life Support -BTLS) e trata das sistematizações de atendimento às vítimas em situações de emergência, seguindo padrões internacionais de atendimento a essas vítimas. São chancelados por instituições internacionais como o Temple College, American Heart Association e o American College of Surgeons.

O curso tem seu início com a abordagem de conceitos básicos sobre Anatomia e Fisiologia Humanas, cuidados relacionados com a Biossegurança, Manobra de Ressuscitação Cardiopulmonar, Suporte Básico de Vida e o Protocolo START (Simple Triage and Rapid Treatment), que se refere ao atendimento com múltiplas vítimas.

O curso foi estruturado com uma carga horária total de 60h e duração de cinco semanas, sendo dividido em seis Módulos (Tabela 1). Os módulos são apresentados em capítulos que, por sua vez, são subdivididos em unidades de ensino que contêm, ainda, exercícios teóricos, trabalhos individuais e em grupo, além de fóruns de discussão e salas de 'bate-papo' que contribuem para a aprendizagem do aluno na fase à distância. O curso é gerenciado e ministrado pela Divisão de Ensino à Distância da Escola de Saúde do HNMD e tem, obrigatoriamente, uma fase presencial de três dias em tempo integral na Escola. São utilizados três instrutores para a fase à distância, e um para a fase presencial, considerando-se grupos de seis alunos nas atividades práticas.

Os recursos necessários para que os alunos possam acompanhar o curso na fase à distância são disponibilizados na OM do aluno ou por agendamento, se forem utilizadas as diversas salas de aula virtuais disponibili- 
zadas nas OMs do SEN. Na fase presencial, a instrutoria utiliza projetores multimídia, manequins instrucionais, manequins vivos maquiados como vítimas em cenários que imitam situações de conflito e dificuldades de resgate.

Importante ressaltar que os instrutores de ambas as fases são Oficiais e Praças Enfermeiros, com curso de formação em Suporte Básico e/ou Avançado de Vida com chancela obtida pela SERV RIO (http://www.cite-brasil.com.br/), instituição credenciada internacionalmente para o exercício profissional.

A avaliação da aprendizagem foi realizada pelos instrutores, que acompanharam a participação dos alunos durante o curso por meio da realização dos exercícios obrigatórios propostos em cada módulo.

De acordo com Alves (2006, p.40-41), "as normas para a avaliação de programas de educação à distância incluem obrigatoriedade de momentos presenciais, sendo que os instrumentos de avaliação dos estudantes devem estar definidos no Projeto Pedagógico do curso.”

A avaliação foi realizada pelos instrutores, que acompanharam a participação dos alunos durante o curso por meio da realização dos exercícios obrigatórios propostos em cada módulo, além de testes e trabalhos em grupo, utilizados também como ferramentas para a avaliação do desempenho de cada aluno.

\section{PROCEDIMENTOS METODOLÓGICOS}

Trata-se de um estudo de caso. De acordo com Martins (2004), o estudo de caso é uma categoria de pesquisa cujo objeto é uma unidade que se analisa profundamente. Pode ser caracterizado como um estudo de uma entidade bem definida, como um programa, uma instituição, um sistema educativo, uma pessoa ou uma unidade social. Visa conhecer o seu “como" e os seus "porquês”, evidenciando a sua unidade e identidade própria. É uma investigação que se assume como particular, debruçando-se sobre uma situação específica, procurando descobrir o que há nela de mais essencial e característico. Na abordagem qualitativa, Minayo (2010) afirma que se verifica uma relação dinâmica entre o mundo real e o sujeito, isto é, um vínculo indissociável entre o mundo objetivo e a subjetividade do sujeito, que não pode ser traduzido em números.

A coleta de dados foi realizada através de diferentes etapas e instrumentos, a saber: análise de documentos, alguns que foram utilizados para constituir informações sobre os sujeitos e o cenário da pesquisa; e outros para a coleta de dados - questionários pedagógicos aplicados na fase a distância. Foram aplicadas por meio de entrevistas semiestruturadas junto a cinco sujeitos da pesquisa, com a finalidade de ampliar o discurso dos mesmos acerca da fase à distância.

Foram utilizados o questionário pedagógico do Departamento de Ensino a Distância (DEAD) da Marinha do Brasil e um roteiro de entrevista. Estes instrumentos diversificados visaram entender as interpretações dos atores envolvidos acerca dos fatos que se apresentarem (Ludke; André, 1986).

Tendo em vista os objetivos do trabalho, foi necessário que a pesquisa de campo se desenvolvesse na Escola de Saúde do HNMD, por ser a única nesta área na Marinha do Brasil. Porém, desde a seleção do tema, a objetividade no trabalho foi buscada para não comprometer a validade do estudo.

Quanto à subjetividade, o constante retorno à teoria serviu de recurso controlador e necessário à fidedignidade da coleta de dados e análise dos mesmos. Somado a isto, conforme Ludke e André (1986), consideramos a clarificação dos critérios utilizados para seleção de dados, aplicação dos questionários, além da explicitação de como os fatos pesquisados afetaram a pesquisa e serviram de "protetores" da objetividade. 


\section{SUJEITOS DO ESTUDO}

Os sujeitos da pesquisa foram cinco Sargentos Enfermeiros, Técnicos em Enfermagem, do sexo masculino, com média de dez anos de serviço ativo na Marinha do Brasil, egressos do Curso de Suporte Básico de Vida à Distância da Escola de Saúde do HNMD, escolhidos aleatoriamente pelo pesquisador. Previamente ao início das entrevistas, todos assinaram o Termo de Consentimento Livre e Esclarecido, conforme previsto na Resolução $196^{3}$ do Conselho Nacional de Saúde, sendo informados acerca dos objetivos da pesquisa, de que em qualquer momento poderiam desistir de participar do estudo sem nenhum prejuízo de qualquer tipo e da garantia de sigilo absoluto acerca do que dissessem nos respectivos depoimentos, mediante utilização de um código alfanumérico (S1 até S5).

As entrevistas foram previamente agendadas e gravadas com anuência dos participantes, sendo realizadas na Escola de Saúde do HNMD, no laboratório de informática vinculado à Divisão de Ensino à Distância. Posteriormente, foram transcritas pelo pesquisador e apresentadas a cada participante, para assegurar a garantia da fidedignidade daquilo que haviam dito.

\section{ANÁLISE DOS DADOS COLETADOS}

Nesta etapa, utilizamos a análise do discurso. De acordo com Maingueneau (2008), a Análise do Discurso Francesa expõe que "discurso" é uma dispersão de textos (ou as falas) transcritos, cujo modo de inscrição histórica será definido como um espaço de regularidades enunciativas. Ou seja, tem uma dupla voz no discurso, heterogeneidade do discurso, que se constitui a partir dessas regularidades produzidas histórica, política e socialmente.

Oliveira (2003): A análise do discurso é a estratégia de pensamento recorrida, visando a que o discurso dos atores institucionais não seja tratado de maneira "conteudista", ou seja, como se existisse nele mesmo ou se tivesse uma causa objetiva exterior (p. 120).

Podemos também considerar a análise de discurso como: Um conjunto de regras anônimas, históricas, sempre determinadas no tempo e no espaço, que definiram em dada época, e para uma área social, econômica, geográfica ou lingüística dada, as condições de exercício da função enunciativa (FOUCAULT apud MAINGUENEAU, 2008, p.16).

\section{ASPECTOS ÉTICOS DA PESQUISA}

Este trabalho obteve parecer favorável do Comitê de Ética em Pesquisa (CEP) do Hospital Naval Marcílio Dias, sob n ${ }^{0}$ 024/2008, segundo as normas éticas vigentes no País para pesquisa envolvendo seres humanos (Resolução nº 196/96 do Conselho Nacional de Saúde).

\section{RESULTADOS E DISCUSSÃO}

\section{1 Categorias para Análise dos Discursos}

- Interação instrutor-aluno na fase a distância do SBV

3 Resolução válida à época da pesquisa, foi substituída pela de nº 466/12 ainda hoje em vigor. 
Em geral, as falas dos entrevistados apontam para uma dificuldade inerente à EaD: falta do estabelecimento da relação professor-aluno na fase a distância, que pode ser evidenciada nos recortes das falas dos participantes, como exemplo apresentamos as dos Sujeitos 1 e 4.

\begin{abstract}
“Bem, na fase à distância eu senti uma relação muito fria. Mesmo sendo à distância, essa relação tem que ser mais próxima do aluno, porque pelo fato de ser à distância, a meu ver... tem que ser mais próxima para evitar que o aluno passe essa fase toda com muitas dúvidas. Com dúvidas vai passar, mas essa dúvida tem que ser a menor possível, em menor quantidade, isso para mim só com um acompanhamento mais próximo entre um aluno e a instrutoria, tutoria, não sei o nome correto (pausa) por isso eu achei fria, um pouco distante entre eu e o curso em si... (pausa) a instrutoria do curso, só acho que isso foi melhor dirimido quando na ocorrência da fase presencial essa relação ficou melhor estabelecida ... (pausa) sem dúvida, a parte presencial foi fantástica, tirou...(pausa) além das dúvidas, acrescentou... (pausa) mas ainda assim eu tive mais dificuldade na fase presencial por conta da grande separação da parte... da parte em que é à distância” (S1: Primeiro-Sargento, com 19 anos de Marinha, sendo 15 anos de exercício profissional em enfermagem)
\end{abstract}

\begin{abstract}
"Eu acho que faltou um pouco de orientação na pesquisa, a orientação de quem já domina o assunto, porque aquele que está pesquisando, com a pesquisa, ele vai gerar alguns questionamentos até mesmo porque ele vai pesquisar em mais de uma bibliografia,, e podem ser até bibliografias antagônicas e por conta disso a pesquisa tem que ter uma orientação no sentido de que seja feita de forma correta, mas a pesquisa é necessária, tem que acontecer, e acho que deveria ser mais sobre mais assuntos.” (S4: graduação de Terceiro-Sargento com 13 anos de Marinha, com nove anos de exercício profissional militar em enfermagem, cursando Enfermagem em nível superior)
\end{abstract}

De acordo com Aretio (2002), todo curso à distância deve usar sistemas de tutoria, uma vez que o mesmo possibilita a comunicação do tutor/professor e aluno, e torna-se um ambiente que propicia a troca de experiências e, por conseqüência, reforça o aprendizado. Para Jaeger e Accorssi (2007), dentre as funções do tutor são citadas: acompanhamento das atividades dos alunos; realização de avaliações e análise dos trabalhos; esclarecimento de dúvidas pelo ambiente virtual de aprendizagem, e-mail, fórum, chats, telefone ou pessoalmente; encaminhamento de dúvidas aos professores e recebimento e controle das atividades.

Nesse sentido, o tutor se constitui como mediador do processo de ensino-aprendizagem, fazendo o papel de "facilitador" da construção do conhecimento pelos alunos. O papel do tutor é o de intermediar as relações de aprendizagem, de ser o facilitador da construção do conhecimento. Assim, podemos usar o conceito de Zona de Desenvolvimento Proximal, um dos mais conhecidos e mencionados da teoria de Vygotsky, para explicar a importância do tutor no seu processo de tutoria.

A zona de desenvolvimento proximal é a distância entre o nível de desenvolvimento real, que se costuma determinar através da solução independente de problemas, e o nível de desenvolvimento potencial, determinado através da solução de problemas sob a orientação de um adulto ou em colaboração com companheiros mais capazes. (VYGOTSKY, 2007, p.97)

Essa análise permitiu modificar a estrutura da parte do ensino à distância do curso, haja vista que a relação ensino-aprendizagem baseada na idéia do mediador precisa ser melhor desenvolvida junto aos atores envolvidos no processo de ensino e aprendizagem. A visão do professor/instrutor/tutor/mediador deve ser trabalhada devido à dificuldade, na fase à distância, da falta da sistematização da sala de aula militar, em que a disciplina e a hierarquia são fatores presentes no processo de ensino-aprendizagem, ainda que com professores civis. No processo de ensino-aprendizagem à distância, o aluno se "despe da farda" e o professor também, e ambos se fazem parceiros no processo, mas com sua autonomia intelectual preservada. Isto pode ser confirmado pelo grande percentual de maior solicitação de tempo na fase presencial.

Durante toda fase à distância, o aluno tem disponíveis ferramentas de interação, onde são discutidas temáticas junto ao tutor em tempo real previamente agendado, quando são determinadas atividades em grupo a serem 
desenvolvidas pelos alunos em seus locais de acesso e, posteriormente, apresentadas como atividade de grupo na fase presencial, ocasião em que as dúvidas sobre os conteúdos são esclarecidas pelo tutor.

Deve-se considerar que a fase à distância também foi analisada levando em consideração as ferramentas de interação tutor $v s$ aluno, que podem ser acionadas diversas vezes, conforme a necessidade do aluno. É uma etapa em que as atividades são estabelecidas para serem desenvolvidas em grupo e apresentadas posteriormente, na fase presencial. Novamente, as falas remetem à questão da forma como se dá o conhecimento, ou seja, como se dá a relação entre aquele que aprende e aquele que ensina. Há referência à condição daquele que ensina como, por exemplo, saber identificar as dificuldades encontradas na elaboração dos trabalhos em grupo que deverão ser apresentados na fase presencial, como foi explicitado por um dos Sujeitos do estudo.

A perspectiva discutida acima permite entender a idéia de individualização do processo de construção de conhecimento, numa abordagem inatista, tal como nos diz o Sujeito 3: "Você vai lá nos arquivos que existe da matéria e retira sua própria dúvida ou você envia uma mensagem ao instrutor e ele vai responder”. Isso retira o professor-tutor da cena da aprendizagem, o que pode estar acontecendo no curso analisado e será objeto de revisão.

\section{2 Professores e alunos compartilhando conhecimentos durante $\mathrm{o}$ curso, na fase à distância}

Deve-se considerar que a fase à distância foi analisada levando em consideração as ferramentas de interação tutor vs aluno, que podem ser acionadas diversas vezes, conforme a necessidade do aluno. É uma etapa em que as atividades são estabelecidas para serem desenvolvidas em grupo e apresentadas posteriormente, na fase presencial. As falas apresentadas a seguir referem-se a ambos os aspectos:

Eu achei que foi deficiente em número de vezes, porém nas vezes em que aconteceram, tirando o chat que não foi melhor por conta dos participantes, não por conta do mediador, mas por conta dos participantes, eu achei que o nível foi fraco. Foi muito interessante, só achei ruim o número de vezes, que tinha que ser muito mais. (...) Extremamente importante... é como se fosse na faculdade presencial, você tem que pesquisar e repartir com o grupo e até apresentar, fato esse que me ajudou no curso, porém é...(pausa) a pesquisa ela tem que ser sempre orientada. Eu acho que faltou um pouco de orientação na pesquisa... é ... a orientação de quem já domina o assunto, que aquele que está pesquisando, com a pesquisa ele vai gerar alguns questionamentos até mesmo porque ele vai pesquisar em mais de uma bibliografia e podem ser até bibliografias antagônicas e por conta disso a pesquisa tem que ter uma orientação no sentido de que a pesquisa seja feita de forma correta, mais a pesquisa ela é necessária tem que acontecer e acho que deveria ser mais sobre mais assuntos. (S1)

No meio virtual foi através do bate-papo, e também através das tarefas que os professores passavam para os alunos e aí era realizado as tarefas e depois foi marcado um bate-papo onde todo mundo conversou. Foi muito boa. (...) É uma excelente forma de aprendizagem por que além de você ter aquele material que você tem na página do ensino a distância, você é obrigado a buscar mais coisas, porque no caso do meu curso, eu tive que fazer um trabalho em grupo, onde eu tive que buscar mais coisas, além do que já estava lá na página para poder apresentar depois. (S2)

Houve sim. Por mais que o instrutor presencial leve um curso que exista barreira entre o educando e o educador, o educando ele tem uma dificuldade muitas vezes de fazer a mesma pergunta de forma diferente, ou tirar uma dúvida que pra ele seria difícil com os demais da turma, que seria idiota, mas a gente sabe que não. Já na questão virtual não, se você tem uma dúvida você vai lá nos arquivos que existe da matéria e você retira sua própria dúvida ou você uma mensagem ao instrutor e ele vai responder. (...) A pesquisa, quando a gente tem hoje em dia a Internet, facilita muito o campo de pesquisa, porém muitas das informações, quando a gente tenta repartir com o grupo na forma virtual nós não temos a certeza absoluta se todos efetivamente leram a parte pesquisada pelo educando, então a gente fica naquela dúvida será que o que eu gostaria que eles tivessem visto eles viram? Eles leram? Ou simplesmente leram sem compreender! Fica uma dúvida. (S3) 
Eu já tinha experiência de um curso extra-Marinha, então, para mim não teve tanto choque. Mas na minha visão, para quem não tem o costume, devido à uma tradição em educação, toma um choque na primeira vez, mas acho que não há problema não. Isso é questão de interação de “habitualidade”. (...) Eu acho que são três fases. A primeira fase é o aluno com o sistema, no caso com a sistemática... eu acho que o aluno se ele absorver, se interessar, ele vai tranqüilo. A segunda, é o lugar em que ele está; se oferecer para ele algum respaldo técnico, uma logística e aí tanto o horário como o instrumento...o computador! Com rede, isso é importante senão não funciona; e outra parte é a aceitação do grupo, o grupo também entrar em contato um com o outro, então há aquele "link". Aí o aluno fez a parte dele, foi motivado, teve o incentivo daqueles que o liberaram pra cursar e também ele fez a terceira parte que é a sociabilidade num ambiente virtual, que é o fórum. Acho que nesse momento é uma das maiores questões que leva o aprendizado do aluno. Se cortar esse "link" aí, acabou. (S4)

Através das ferramentas que são disponibilizadas, se você realmente se interessar pelo curso e se aprofundar na ferramentas que são oferecidas eu acho que você tem aprendizado. (...) Achei essa dinâmica interessante porque exige de você que realmente pesquise para você poder compartilhar com outro grupo, todos os membros do grupo. (S5)

Novamente, as falas remetem à questão da forma como se dá o conhecimento, ou seja, como se dá a relação entre aquele que aprende e aquele que ensina. Há referência à condição daquele que ensina como, por exemplo, saber identificar as dificuldades encontradas na elaboração dos trabalhos em grupo que deverão ser apresentados na fase presencial, como foi explicitado por um dos Sujeitos do estudo:

Eu acho que faltou um pouco de orientação na pesquisa, a orientação de quem já domina o assunto, porque aquele que está pesquisando, com a pesquisa, ele vai gerar alguns questionamentos até mesmo porque ele vai pesquisar em mais de uma bibliografia,, e podem ser até bibliografias antagônicas e por conta disso a pesquisa tem que ter uma orientação no sentido de que seja feita de forma correta, mas a pesquisa é necessária, tem que acontecer, e acho que deveria ser mais sobre mais assuntos. $\left(\mathrm{S}_{4}\right)$

A importância do papel do professor está dada na fala do entrevistado - “a orientação de quem já domina o assunto”. Podemos entender isso a partir do conceito de desenvolvimento potencial apresentado por Vygotsky apud Rego (2000, p. 73): "o nível de desenvolvimento potencial se refere àquilo que a criança é capaz de fazer, só que mediante a ajuda de outra pessoa”. Ou seja, aquele que aprende precisa do discurso do OUTRO, mais experiente, para que consiga dar significado àquilo que está em vias de aprender, até que o conteúdo se torne, como diria Vygotsky, desenvolvimento real, aquilo que o indivíduo já é capaz de dar significado sem ajuda do OUTRO. Assim, sem “a presença” desse OUTRO, fica impossível constituir conhecimento.

Entretanto, é preciso deixar claro que esse OUTRO não precisa estar necessariamente presente no mesmo espaço daquele que aprende, mas deve haver, sim, no caso da EaD, a busca de metodologias para o espaço virtual que permita esse diálogo entre mediador e aluno evitando, assim, um caráter instrucionista. Esse momento de aprendizagem não pode ser identificado pelo aluno como simples "bate-papo", como foi dito pelo Sujeito 2.

A perspectiva discutida acima permite entender a idéia de individualização do processo de construção de conhecimento, numa abordagem inatista, tal como nos diz o Sujeito 3: "Você vai lá nos arquivos que existe da matéria e retira sua própria dúvida ou você envia uma mensagem ao instrutor e ele vai responder".

Esse papel professor-tutor como mediador pode ser conseguido com a valorização de algo dito na fala do Sujeito 4: "A sociabilidade num ambiente virtual que é o fórum. Acho que nesse momento é uma das maiores questões que leva o aprendizado do aluno. Se cortar esse "link", aí acabou". Isso remete à idéia de que a troca de conhecimentos, de discursos, evidencia a proposta de que a construção de conhecimento deve ser coletiva, porque é sempre a partir do significado constituído a partir da experiência do OUTRO que se dá ao conteúdo a ser ensinado a certeza de que é possível aprendê-lo. 


\section{3 Relação máquina vs tutor vs aprendiz}

Não, não vejo dificuldade alguma, desde que tutor esteja mais próximo do aluno mesmo que virtualmente, mas não vejo problema quanto a isso não. (S1)

Olha... sempre há alguma dúvida que fica, alguma coisa que você não acha logo de primeira, mas isso daí no decorrer do curso você vai sanando, você se adequando a linguagem que é utilizada pelo Sistema. Logo de princípio no meu caso..., como eu nunca tinha feito nenhum curso de ensino a distância, eu senti que tinha algumas coisas que eu teria que dar mais ênfase, mas logo depois foi muito fácil. (S2)

Não. Eu não vejo dificuldade, embora a máquina hoje em dia, ela facilita a digitação, aquela coisa toda, eu acho que fica bem interessante. Se tivesse uma ferramenta de webcam que a gente está vendo o instrutor seria muito interessante. (S3)

Há dificuldade se não houver uma dessas partes ...tirou uma dessas partes aí, eu acho que há dificuldades. Lembrando que se não houver apoio logístico da própria Organização Militar em que o militar se encontra, se não houver então vai ser mais uma dificuldade. (S4)

Não, não tive dificuldade de lidar com ferramenta não, talvez porque os computadores estão muito presentes hoje em dia, não é um instrumento distante da realidade atual. (S5)

Mesmo tendo que lidar com questionamentos sobre o uso do computador como espaço de aprendizagem, os entrevistados ainda ressaltaram o papel do professor como, por exemplo, na fala do Sujeito 1, que relatou o que foi dito acima quanto à presença do tutor na $\mathrm{EaD}$; ou seja, o professor não precisa estar necessariamente presente no mesmo espaço daquele que aprende, mas deve haver a possibilidade de construção de um diálogo.

Além disso, a ideia de que a aprendizagem se dá pela única ação daquele que aprende apareceu novamente trazendo, mais uma vez, uma abordagem inatista da construção do conhecimento:

Olha... sempre há alguma dúvida que fica, alguma coisa que você não acha logo de primeira, mas isso daí no decorrer do curso você vai sanando, você se adequando a linguagem que é utilizada pelo Sistema. Logo de princípio no meu caso..., como eu nunca tinha feito nenhum curso de ensino a distância eu senti que tinha algumas coisas que eu teria que dar mais ênfase, mas logo depois foi muito fácil. (S2)

\section{4 Contribuições para a vida profissional geradas pelo curso SBV à distância}

Diretamente nenhuma [contribuição], porque eu não exerço a função de enfermeiro, mas para aquele que exerce é sobremaneira excelente, fantástico, importantíssimo, eu acho que afeta diretamente a vida. Ele, o enfermeiro comum, comum que eu digo é o que não tem essa visão do SBV, ele passa a não ser mais comum. (S1)

Indagado acerca do grau de importância que esse curso teria em sua vida profissional, do ponto de vista militar inserido em um contexto como enfermeiro, atuando em uma área operativa dentro de um navio, ele respondeu: 
Numa escala de 0 a 5, seria 6. É assim, tanto o ESP quanto a AP, ambos possuem a disciplina de emergência pelo menos na minha época não supria de forma alguma o SBV, que por si só eu vejo como uma subespecialidade de tamanha importância no curso que eu vi ao fazê-lo é...(pausa), o Cabo, o Sargento recém formado não tem como agir principalmente na parte operativa. Vamos botar no caso da gola ("da gola"são os militares do Corpo da Armada da Marinha do Brasil.) no navio, não tem como agir no caso de guerra, ou até mesmo em tempo de paz, mas enfim, em caso em que seja necessário agir dessa forma com o suporte básico de vida, o paciente no caso, ferido, vai sofrer muito para ser salvo, diferentemente de um enfermeiro que possua o $S B V$, que saberá agir de maneira muito mais direta e efetiva sobre a ocorrência. (S1)

O Sujeito 2 respondeu o seguinte:

Contribui para o aprendizado, é adicionar ao meu conhecimento técnico que eu já tinha com relação ao suporte básico de vida, foi um "quê" a mais, foi uma nova esfera que eu pude visualizar também. (S2)

Quando perguntado sobre sua vida profissional e o período em que passou embarcado, com a maturidade profissional que possui, e se considerava que as contribuições do curso de suporte básico de vida a distância fariam com que se sentisse mais seguro para atuar numa situação de embarque imediato, sabendo que nem sempre tem um médico presente e que o enfermeiro pode estar diante de uma situação de risco de vida, de grave ocorrência, o mesmo entrevistado respondeu prontamente:

Poxa, isso eu posso dizer, porque já estive dos dois lados. Já trabalhei numa fase em que eu tinha acabado de sair do ESP e fui trabalhar num local onde pegava-se muitos pacientes graves e não tinha conhecimento. Eu posso dizer de carteirinha que com o suporte básico de vida, a visão é completamente diferente... para quem está cego, é uma luz no fim do túnel. (S2)

O Sujeito 3 pronunciou-se também sobre o assunto que estava sendo abordado:

Como eu falei anteriormente, eu passei por vários cursos e em cada curso tínhamos uma tendência a adaptar o que o instrutor sempre nos trazia. Com relação à enfermagem em si, o conteúdo a distância, ele veio somar a parte técnica da enfermagem, eu não via mais a questão de primeiros socorros num suporte básico de vida como militar em área de conflito, eu via como um profissional de saúde que tinha que ter um conhecimento mais apurado para poder satisfazer a minha vítima, fazer um atendimento à minha vítima com maior eficácia, então, o curso propicia tal momento como profissional de saúde. (S3)

Ao ser indagado sobre manobras e missões, embarque em navios e manobras em áreas e/ou condições inóspitas, se pudesse fazer hoje um comparativo entre as manobras que fez em todas essas condições difíceis, antes e após a realização do curso, referiu-se às contribuições que o aprendizado havia oferecido em relação ao seu desempenho profissional, ele respondeu:

Ele abriu um horizonte e da mesma forma que ele abriu um horizonte no tocante a Especialidade, ele me deu ma outra visão operacional. Um exemplo que vejo hoje uma necessidade maior de carregar um pouco mais de peso. Então o que a gente fazia tradicionalmente que era carregar um bornal que continha determinadas coisas, hoje em dia eu vejo que preciso carregar algo mais, pois é algo mais que vai fazer a diferença pra minha vítima até chegar no intra-hospitalar. Enfim, o contato com a minha vítima agora, neste momento se houver alguma... espero que não..., mas se tiver estarei pronto para tal, vai ser diferente, por que eu vou tratar essa vítima preparando ela pra chegar no intra hospitalar. Eu não vou prepará-la apenas para continuar a missão. Eu vou prepará-la pra ela chegar no intra hospitalar sem seqüela nenhuma. (S3)

O Sujeito 4 referiu-se à realização do curso a distância, considerada uma experiência válida, conforme explicou: 
Primeiro é entender como é que funciona um curso na área de saúde a distância que alguns acham que é de baixo nível, digo na graduação, se você colocar nota, eu diria que é do mesmo nível dos cursos presenciais, mas para mim, me atualizou até para entender como funciona a parte virtual. (S4)

Acerca de questões relacionadas ao embarque, questionado se os conhecimentos do curso contribuiriam para melhorar a atuação profissional neste contexto, ele respondeu:

Contribuiriam muito (...) depois disso não dá mais para voltar atrás; para quem não tem acesso, não tem tempo para vir e cursar da forma exclusivamente presencial, cairia como uma luva, e até para algumas OM que não tenham condições de suportar outros cursos que não sejam de Marinha, esse curso já atinge pessoas em lugares que a gente nem imagina. (S4)

O Sujeito 5 destacou a importância do curso a distância para os profissionais de enfermagem em geral:

\begin{abstract}
Quando se tem a formação de enfermagem aqui na Escola de Saúde, a gente tem uma formação assistencial, que fica um pouco distanciado da questão do pré-hospitalar, aí quando você vem e faz um curso como o de suporte básico de vida e começa a criar um caminho sobre a questão do pré-hospitalar e é passada a importância desse primeiro atendimento prestado à vítima, você manter ali a viabilidade dos órgãos nobres até um suporte avançado é fundamental, eu acho que todo técnico ou auxiliar de enfermagem deveria ter acesso a esse tipo de informação. (S5)
\end{abstract}

Quando foi indagado se considerava que haveria mais facilidade de ação assistencial após o curso, caso estivesse embarcado cumprindo alguma missão, sendo ele o enfermeiro de bordo, respondeu:

Com certeza facilitaria ... como havia falado, aqui a gente tem na Escola de Saúde uma formação para o assistencial e o curso de SBV, ele vem abrindo os caminhos para o atendimento pré-hospitalar, que vai permitir que se faça um atendimento a essa vítima, mantendo uma viabilidade melhor, porque os conhecimentos são passados até a chegada do suporte avançado, ou seja, prepara melhor o enfermeiro para estar atuando isoladamente, num caso de estar embarcado. (S5)

Destaque deve ser dado à fala do Sujeito 4, escolhida por ser emblemática no que tange às discussões atuais quando se trata da EaD diante da educação regular, presencial, pois ele identifica o mesmo nível e, logo em seguida, indaga qual seria a finalidade da EaD. A resposta para o questionamento é que a EaD surgiu com a perspectiva de possibilitar acesso ao conhecimento àqueles que não estão em locais possíveis para a realização da educação presencial. Essa é a finalidade do curso analisado.

Verificou-se, portanto, que a obtenção de conhecimentos em situações de emergência em suporte básico de vida será facilitada a partir de possibilidades educativas disponibilizadas por meio de recursos tecnológicos, como a rede mundial de computadores, que podem facilitar o aprendizado de militares que se encontrem distantes de pólos educacionais presenciais para o aprendizado de manobras de salvamento, conforme protocolos de atendimento preconizados internacionalmente.

\title{
9 ANÁLISE DOCUMENTAL
}

Foram analisados questionários pedagógicos da fase a distância de duas turmas realizadas em 2006, três em 2007 e quatro turmas em 2008. Esses dados foram coletados por meio de documentos ostensivos da Marinha do Brasil, entenda-se Escola de Saúde do HNMD, cujo Comitê de Ética em Pesquisa autorizou a análise e divulgação dos dados compilados. No total, 115 alunos participaram respondendo ao questionário.

O questionário foi dividido em partes:

a) “Conteúdo Programático e Método de Avaliação”, 
b) “Acesso ao Curso”.Quando perguntados sobre os conceitos transmitidos, $100 \%$ dos estudantes afirmaram que o curso atendeu às suas necessidades. Este alto índice de respostas indica que houve uma correspondência entre as expectativas dos estudantes, profissionais de enfermagem de nível médio e os conhecimentos desenvolvidos no curso. Importante ressaltar que todos os alunos também afirmaram que os conceitos transmitidos e a linguagem utilizada foram de fácil compreensão, visto que os alunos já detinham o domínio das terminologias e situações apresentadas.

Nesse contexto, esses resultados vão ao encontro da Teoria da Aprendizagem Significativa de Ausubel (2003). Para Ausubel, é fundamental a valorização dos conhecimentos prévios dos alunos, uma vez que tais conhecimentos servem para o “ancoramento” de novas informações. Assim sendo, é a partir dos conhecimentos prévios que as atividades de ensino necessitam ser desenvolvidas.

Em relação ao horário, o melhor período para acessar o curso foi de: 23,08\% dos estudantes optaram pelo período da manhã, 38,46\% para a tarde e outros 38,46\% para a noite. Esse resultado é explicado pelo fato das Organizações Militares apresentarem um fluxo de atividade maior no período da manhã, o que dificulta ao militar deixar de cumprir com suas funções para poder acessar o curso. O fato da maior prevalência de acesso ocorrer nos períodos da tarde e noite é justificada em virtude das OM de saúde funcionarem em dois turnos e com a facilidade de acesso pela Internet, o aluno acompanhava as atividades em seu domicílio.

Importante mencionar que alguns militares podem ser destacados para embarques não previstos e devido ao cumprimento de escalas de serviços em OM de mar, que apresentam rotinas diferentes de terra e, além disso, há áreas de navegação com dificuldades de acesso à Internet.

Ao serem perguntados se houve algum tipo de dificuldade junto às suas chefias imediatas para realizar o curso, 38,46\% dos estudantes responderam positivamente. Isso ocorre porque, muitas das vezes as chefias não possuem o conhecimento do nível de exigência do curso. Existem atividades que são desenvolvidas, por exemplo, em tempo real (nas salas de bate-papo) e como há o desconhecimento das chefias sobre as características do EaD, há dificuldades da liberação dos estudantes para o cumprimento de algumas etapas fundamentais no desenvolvimento do curso.

\section{CONSIDERAÇÕES FINAIS}

O impacto causado pela implantação do curso de Suporte Básico de Vida à Distância foi percebido pela grande procura identificada quando da divulgação, em meios de comunicação interna da Marinha do Brasil, e a abertura de novas turmas. As ferramentas disponibilizadas no ambiente virtual de aprendizagem facilitaram os processos de interação das salas de aula virtual, fato observado quando algumas vezes, durante as madrugadas, identificamos grupos de aprendizes em salas de bate-papo “teclando” sobre as temáticas do curso e a apresentação de atividades na fase presencial.

O Curso “Suporte Básico de Vida a Distância”, via web, é o único entre as Forças Armadas e Auxiliares nesta modalidade, atendendo não só aos militares da localidade, como também àqueles embarcados em hospitais distritais.

Os resultados da pesquisa de campo, baseados nas entrevistas, apontam à importância do curso e à oportunidade de adquirir novos conhecimentos por computador. Porém, dificuldades foram encontradas para sensibilizar os Comandos Militares de que, uma vez matriculado, o militar necessita cumprir as atividades do curso cujas regras, mesmo a distância, precisam ser cumpridas sob pena de uma reprovação que poderá comprometer sua carreira militar. Tais dificuldades estavam relacionadas às obrigações com as atividades diárias a distância, visto que o militar não é destacado de sua OM para cursar como tradicionalmente ocorre no ensino presencial, 
exceto para cumprimento de etapa correspondente e, a sua rotina laboral por vezes não pode ser comprometida em função da necessidade de um curso a distância.

O Curso de Suporte Básico de Vida a Distância, desde sua implantação em 2006 até os dias atuais, devido à grande procura por militares e Comandos das $\mathrm{OM}$, tem sido utilizado com a preocupação de manter profissionais preparados para atuação em situações de emergência em saúde. Considera-se comprovada a relevância do alcance dos objetivos desse estudo, com os reflexos positivos junto à Diretoria de Ensino da Marinha (DEnsM) ao reconhecer a importância para o aprendizado de nossos militares e à Diretoria de Saúde da Marinha (DSM), que busca qualificar os militares para uma atuação com resultados eficazes, estimulando a criação de outros cursos na mesma modalidade. 


\section{REFERÊNCIAS}

ABREU, L.E.L. Meia volta volver - um estudo antropológico sobre a hierarquia militar. Rev Antropol, São Paulo, v. 41, n. 1, p.237-245, julho/dez,1998.

ALCANTARA, L.M. A Enfermagem militar operativa: gerenciando o cuidado em situações de guerra. 288p. Rio de Janeiro, julho, 2005. Tese [Doutorado em Enfermagem], Escola de Enfermagem Anna Nery, Universidade Federal do Rio de Janeiro, 2005.

ALVES, J. R. M. A nova regulamentação da EAD no Brasil. In: SILVA, Marco (Org.) Educação Online. 2.ed. São Paulo: Loyola, 2006.

ARETIO, Lorenzo García. La educación a distancia: de la teoria a la práctica. Barcelona: Ariel, 2002.

AUSUBEL, D.P. Aquisição e retenção de conhecimentos: uma perspectiva cognitiva. Portugal: Plátano, 2003.

CÂMARA,V.G. A construção da identidade professoral militar: um estudo de caso sobre docentesenfermeiros da escola de saúde da Marinha do Brasil. 83 p. Rio de Janeiro, maio, 2008. Dissertação [Mestrado em Educação], PUC-Rio, Departamento de Educação. 2008.

CHARAUDEAU, P.; MAINGUENEAU, D. Dicionário de análise do discurso. 2.ed., 2. reimpressão. Coordenação da tradução: Fabiana Komesu. São Paulo: Contexto, 2008.

DEnsM-5001. Manual para elaboração de cursos a distância, da Diretoria de Ensino da Marinha, OSTENSIVO - Marinha do Brasil (2005). 86 páginas.

FLYN, R. R. Computer Sciences: Ideas and Peoples. $1^{\text {st }}$ ed. V. 1. New York: The Macmillan Science Library, 2002.

GOFFMAN, E. Manicômios, Prisões e Conventos. São Paulo: Perspectiva, 2005.

JAEGER, F.P.; ACCORSSI, A. Tutoria em Educação à Distância. Disponível em: <http://www2.abed.org.br> . Acesso em: 17 mar. 2012.

LEIRNER, P. Meia volta volver - um estudo antropológico sobre a hierarquia militar. Rio de Janeiro: FGV, 1997. $124 \mathrm{p}$.

LÉVY, P. As Tecnologias da Inteligência: o futuro do pensamento na Era da Informática. Rio de Janeiro: Editora 34, 1993.

LUCENA, M. Teoria Histórico-Sócio-Cultural de Vygotsky e sua aplicação na área de tecnologia educacional., Rio de Janeiro, v.26, n. 141, p. 49-53, abr./jun., 1998.

LÜDKE, M. Pesquisa em Educação: abordagens qualitativas. São Paulo: EPU, 1986.

MAGGIO, M. O tutor na Educação à Distância. In: LITWIN, E. (Org.) Educação à Distância: temas para o debate de uma nova agenda educativa. Porto Alegre: Artmed, 2001. p. 93-101

MAINGUENEAU, D. Gênese dos discursos. Trad. Sírio Possenti. São Paulo: Parábola Editorial, 2008.

MARTINS, H.T.S. Metodologia qualitativa da pesquisa. Educação e Pesquisa, São Paulo, v. 30, n. 2, p. 287298, maio/ago., 2004 
NUNES, I.B. A História da EAD no Mundo. In: LITTO, F.M.; FORMIGA, M.M. (orgs.). Educação à Distância: o estado da arte. São Paulo: Pearson Education do Brasil, 2009.

OLIVEIRA, L.R. Sujeito como interface entre a escola que reproduz e que transforma. São Paulo, 2003. Tese [Doutorado em Educação], Universidade de São Paulo, Brasil, 2003.

PALLOF, R. M.; PRATT, K. Construindo comunidades de aprendizagem no ciberespaço. Porto Alegre:Artmed, 2002.

PERRENOUD, P. Avaliação - da excelência à regulação das aprendizagens: entre duas lógicas. Porto Alegre: Artmed, 1999.

Práticas Pedagógicas, profissão Docente e Formação - perspectivas sociológicas. Portugal: Publicações Dom Quixote, 1993.

PETERS, O. Didática do ensino à distância. São Leopoldo: UNISINOS, [s.d.].

POLIT, D.F.; BECK, C.T.; HUNGLER, B.P. Fundamentos da Pesquisa em Enfermagem: métodos, avaliação e utilização. Trad. Ana Thorell. 5.ed. Porto Alegre: Artmed, 2004.

A prática reflexiva no ofício professor: profissionalização e razão pedagógica. Porto Alegre: Artmed, 2002.

REGO, T.C. Vygotsky: uma perspectiva histórico-cultural da Educação. 10. ed. Petrópolis: Vozes, 2000.

A inteligência coletiva: por uma antropologia do ciberespaço. São Paulo: Loyola, 1998.

SILVA, M. (org.). Educação online. São Paulo: Loyola, 2006.

STATS, I.W. (2012, 28/04/2012). Internet world stats: usage and population statistics. Retrieved 23/05/2012, from http://www.internetworldstats.com/stats.htm.

TARDIF, M. O trabalho docente: elementos para uma teoria da docência como profissão de interações humanas. Trad. João Batista Kreuch. Petrópolis: Vozes, 2005.

VALLE, E.R.M. A pesquisa participante como metodologia da pesquisa em enfermagem. Rev. Enfoque., São Paulo, v.16, n.1, p.20-23, mar.,1988.

VALLIN, C.; Educação à Distância via Internet. São Paulo: Avercamp, 2003.

VASCONCELLOS, M.D. Pierre Bourdieu: a herança sociológica. Educ Soc., v. 23, n. 78, p. 553573, abril, 2002.

VYGOTSKY, L.S. A formação social da mente. 7.ed. Rio de Janeiro: Martins Fontes, 2007. 